\title{
Notas metodológicas sobre o uso de dados empíricos no estudo das Mercocidades
}

Methodological notes on the use of empiric data in the study of Mercocidades

Ana Paula Lopes Ferreira ${ }^{1}$

\section{RESUMO}

O objetivo deste trabalho é mostrar como utilizar dados empíricos na pesquisa e estudo da participação internacional de cidades por meio das redes, como no caso da Rede de Mercocidades, indicando a pertinência de sua utilização, assim como as dificuldades em usála na busca de dados sobre a temática. Este trabalho não pretende apresentar os resultados da pesquisa ao qual o método se aplica, mas sua utilidade e conveniência na coleta de dados empíricos nas circunstâncias descritas.

Palavras-chave: Dados empíricos; Mercocidades; Metodologia.

\begin{abstract}
The objective of paper is to show how to utilize empiric data in research and study of international role of cities by subnational net as Mercocidades, indicating the relevance of its utilization as well as the difficulties of using it in the research of data on the subject. This work does not intend to present the results of a research, but the utility and convenience of the use of the empiric data.
\end{abstract}

Key words: empiric data; Mercocidades; methodology

\section{INTRODUÇÃO}

A proposta deste texto é mostrar o uso de dados empíricos na pesquisa e estudo das cidades como agentes internacionais que passam, cada vez mais, a atuarem em sistema de redes horizontais, ou seja, de cooperação descentralizada - sem participação de seus governos nacionais. No caso, utiliza-se como a Rede de Mercocidades fundada em 1995 e situada na América do Sul, não limitando-se apenas às cidades que situam-se nos Estados-membros do bloco regional denominado Mercosul. Desse modo, busca-se discutir a pertinência da utilização de uma determinada fonte que disponibiliza dados plurais,

\footnotetext{
${ }^{1}$ Doutoranda em Ciência Política da Universidade Federal do Rio Grande do Sul (UFRGS), Porto Alegre, Brasil. Conjuntura Global, Vol. 4, n. 1, jan./abr., 2015, p. 10-17. 
desde atas até informativos e calendários de reuniões onde a análise de conteúdo responderia da melhor forma. Contudo, em uma necessidade de analisar um número grande de agentes - no caso as cidades-membros - é preciso ampliar a metodologia, fazendo mão, por exemplo, da transformação de dados qualitativos em quantitativos.

No estudo das Relações Internacionais é raro, por exemplo, o uso de dados empíricos na análise de temáticas para medir o grau de participação de um determinado agente em redes de cooperação. Ao escolher estudar a participação das cidades nas Unidades Temáticas da rede Mercocidades foi necessário, primeiramente, definir as variáveis a serem analisadas, para então coletar e transformar dados qualitativos em quantitativos. Desse modo, torna-se possível trabalhar com estatística descritiva, mais especificamente com a distribuição de frequências para compreender a organização dos dados de acordo com as ocorrências dos diferentes resultados observados e assim mensurar como se deu a participação dessas cidades na Rede (BARBETTA, 2006).

Para contextualização geral sobre a Rede de Mercocidades, essa foi criada em 1995 por onze cidades sul-americanas e hoje conta com quase 300 membros. Em sua estrutura existem dezesseis Unidades Temáticas que correspondem à agendas especializadas das cidades, passando desde a Cultura, Juventude, Gênero e Município até Estratégias de Inserção e Cooperação Internacional. De modo geral as Unidades Temáticas permitem o diálogo dos governos subnacionais, bem como a troca de informações do âmbito local e regional, a transferência de políticas públicas e a ação coletiva em defesa de um interesse comum, como a maior participação das cidades nos processos de integração regional, por exemplo. Cada Unidade Temática em seu site oficial - Portal das Cidades disponibiliza a maioria dos documentos produzidos durante os encontros de cidades. $\mathrm{Na}$ seção Documentos estão diversas atas e outros materiais que registram a participação e as temáticas envolvidas, variando em tempo e quantidade conforme a Unidade Temática Pesquisada.

As atas das reuniões das Unidades Temáticas, de 1995 até 2015, foram base para alimentar uma planilha que destaca as principais informações apresentadas na fonte. Ao todo foram utilizadas para a coleta dos dados atas provenientes de 211 reuniões de 14 Unidades Temáticas da Rede Mercocidades: Ambiente e Desenvolvimento Sustentável; Autonomia, Gestão e Participação; Ciência, Tecnologia e Capacitação; Cooperação Conjuntura Global, Vol. 4, n. 1, jan./abr., 2015, p. 10-17. 
Internacional; Cultura; Desenvolvimento Econômico; Desenvolvimento Social; Desenvolvimento Urbano; Educação; Gênero e Município; Juventudes; Planejamento Estratégico; Segurança Cidadã e Turismo². As Unidades Temáticas Integração Fronteiriça e Grupo de Comunicação ficaram de fora da coleta devido a sua recente criação e não disponibilização de dados até o presente fechamento da pesquisa.

A partir dessa experiência de análise empírica, o presente trabalho tem como objetivo essencialmente metodológico mostrar como se deu a coleta de dados e as dificuldades encontradas nesse processo. Porém, é necessário ressaltar que este trabalho não é a apresentação dos resultados da pesquisa que o originou, mas trata-se da utilidade e conveniência do uso de determinadas fontes de pesquisa na implementação de métodos mais assertivos para analisar alto número de casos ( $\mathrm{N}$ grande). Deste modo, não são contemplados elementos de fundamentação teórica, como perspectivas construtivistas, liberais ou realistas, mas tão somente questões de método para coleta e cruzamento de dados empíricos. A interpretação dos mesmos levaria a uma nova discussão que não se aplica no presente artigo. $\mathrm{O}$ objetivo principal é precisar a contribuição da fonte utilizada a partir de um caso específico de pesquisa com um $\mathrm{N}$ grande que ode ser ilustrado no caso da cooperação descentralizada de cidades por meio de suas organizações.

Para tanto, este trabalho será divido em dois momentos: no primeiro momento será apresentada a fonte utilizada - atas das reuniões das unidades temáticas - com suas características básicas e o conteúdo das informações nelas constantes; no segundo momento serão apresentadas as dificuldades encontradas na utilização do instrumento e as soluções empenhadas para resolvê-las. Por fim reforça-se os principais pontos diante da utilização de uma análise quantitativa sobre dados adquiridos por meio qualitativo.

\section{A fonte de dados}

“Mercocidades é uma rede de cooperação horizontal integrada atualmente por 293 cidades de Argentina, Brasil, Paraguai, Uruguai, Venezuela, Chile, Bolívia, Colômbia e Peru, que promove a inserção das mesmas no processo de integração regional do Mercosul" e as "Unidades Temáticas surgem dando resposta à necessidade de

\footnotetext{
${ }^{2}$ Informações sobre as unidades temáticas disponíveis em: http://www.mercociudades.org/node/2286 Conjuntura Global, Vol. 4, n. 1, jan./abr., 2015, p. 10-17.
} 
Mercocidades de trabalhar em determinados aspectos de alta preocupação na Rede e nas cidades"3. A partir destas duas definições, buscamos compreender como se deu a participação destas 293 cidades nas 15 unidades temáticas da rede. Para tanto, a fonte de dados utilizada na pesquisa partiu do site da rede Mercocidades, que a partir deste momento será referenciado como "Portal das Cidades", responsável por disponibilizar os documentos referentes as unidades temáticas como planos de trabalho, convocatórias, atas de reuniões entre outras publicações.

O Portal das Cidades proveu para a presente pesquisa dados significativos sobre a participação de 237 cidades nas unidades temáticas entre 1995 e 2014. A fonte serviu como base para alimentar uma planilha que destaca as seguintes informações: cidade, país, o número de vezes que foi sede e/ou coordenadora de cada unidade temática e o número de vezes que participou das reuniões de cada uma das unidades temáticas. A partir destas informações foram criadas escalas para mensurar a participação destas cidades, em quais áreas elas mais atuam e quais países tem maior representatividade dentro das unidades temáticas. Esse tipo de estudo permite compreender a dinâmica dessa rede de cooperação internacional, uma vez que possibilita mapear as áreas de interesse de cada parte envolvida, contribuindo para uma análise abrangente sobre a temática.

\section{Material empírico e desafios da pesquisa}

O material utilizado para alimentar a planilha foram as atas das reuniões das unidades temáticas, disponíveis em português e espanhol. 0 primeiro desafio foi escolher quais informações considerar na montagem do banco de dados. Como se trata de um N de pesquisa alto, optamos por trabalhar com poucas variáveis, atentando apenas à participação destas cidades e não aos conteúdos propostos ou posições defendidas. Outro motivo que levou a esta escolha foi o fato de que nos arquivos constam, de forma geral, informações não padronizadas. Estes documentos não são homogêneos, em muitos deles não constavam informações como quem eram as cidades coordenadoras e subcoordenadoras da reunião e o posicionamento dos representantes das cidades sobre assuntos em pauta nas reuniões. A solução encontrada para esta situação foi verificar

\footnotetext{
3 Definição disponível em: http://www.mercociudades.org/pt-br/node/2251 Conjuntura Global, Vol. 4, n. 1, jan./abr., 2015, p. 10-17.
} 
quais cidades haviam sido escolhidas para assumir a coordenação e subordinações da unidade temática no ano em que ocorreu a reunião da presente ata.

Outra falha das atas, em muitos casos, é não especificar qual o país de origem das cidades em questão, o que dificulta a coleta, uma vez que há várias cidades com o mesmo nome em países diferentes, deste modo foi necessário realizar uma pesquisa a parte para verificar quais cidades fazem parte ou não da rede Mercocidades. Soma-se a esse desafio a ausência de documentos referentes à unidade temática "Integração Fronteiriça", que levou à exclusão desta unidade temática na análise do objeto. Durante o período de janeiro a abril deste ano (2015), quando a coleta de dados foi realizada, não houve qualquer inclusão de documentos referentes a esta unidade no Portal das Cidades, o que impossibilitou o estudo da participação das cidades nesta unidade.

Por fim, o maior problema de eleger as atas como fonte de dados foi a falta de atas disponíveis em algumas unidades temáticas, e as que estão disponíveis, foram colocadas de maneira aleatória e sem ordem cronológica com algumas lacunas - alguns anos em determinadas Unidades Temáticas não possuem registro disponível de suas atividades. Com isso fica impossibilitada a avaliação da população total, bem como uma avaliação com exatidão. Contudo, pode-se extrair uma avaliação significativa por meio da representação e estatística dos dados diante da participação das cidades, uma vez que o número absoluto não está disponível opta-se por trabalhar com o todo disponível e exercitar a projeção para uma análise mais próxima possível das modas, médias e medianas referentes ao número de vezes que as cidades participaram no total das Unidades Temáticas da Rede ao longo dos anos.

Nesse cenário a melhor opção é a de trabalhar com médias de participação a partir do número de documentos disponíveis. A Unidade Temática com menor número de atas é a "Autonomia, Gestão e Participação", com apenas 5 (cinco) atas disponíveis no Portal das Cidades, enquanto a unidade "Turismo" apresenta o maior número de documentos disponíveis, um total de 30 (trinta) atas. Dessa forma as variações entre as fontes também exigem maior cuidado para não interpretação errônea dos dados. Por exemplo, em uma coleta por representação/média de participação entre todas as cidades torna-se válido o método. Contudo, caso haja afirmações como "as cidades 'preferem' ou 'atuam mais' em uma Unidade Temática do que em outra" não pode ser empregada, visto Conjuntura Global, Vol. 4, n. 1, jan./abr., 2015, p. 10-17. 
que nem todas as atas existentes foram disponibilizadas. Ao todo 436 atas foram disponibilizadas, com uma média de participação de 5 cidades por Unidade Temática ao ano.

Dados possíveis de se retirar encontram-se na repetição de cidades em mais de uma Unidade Temática, bem como aumento de participação representativa, ou seja, se as cidades analisadas ao longo do tempo e da frequência ampliaram atividades em determinados períodos, como em mudanças de governo locais. Também pode-se identificar, pelos cargos de coordenação das Unidades Temáticas as cidades com maior grau de influência sobre os desdobramentos dos temas de cada qual, bem como de seus membros. Cidades mais ativas podem tender a modelar os dados, ou seja, a determinar traços e costumes na realização, por exemplo, na organização das agendas da Rede.

Dessa forma a análise de dados em um $\mathrm{N}$ alto, ainda que não com a totalidade dos dados podem ser coletados de fontes não-quantitativas e transformadas em dados quantitativos com as ressalvas apresentadas. E com a construção de um banco de dados com as variáveis bem definidas - localização nacional da cidade, natureza da cidade (local, regional, global), frequência de participação, coordenação, envolvimento com transferência de políticas públicas e organização de encontros em seu território, por exemplo - possibilitam o cruzamento de dados que pode identificar quais as cidades com maior representação dentre as demais, bem como os valores nacionais mais presentes e seus modelos de políticas públicas - se argentino ou brasileiro. Também torna-se possível a identificação da saúde da Rede, ou seja, se há uma maior produção de atas e participações ao longo dos anos pode-se deduzir um aumento generalizado das atividades da organização que poderia estar se fortalecendo.

De modo geral, após controlar as fontes de dados - atas - e extrair os dados diante das variáveis selecionadas - nomes de cidades presentes em cada ata, por exemplo diversos outros dados são identificados mesmo não estando presentes, como a localização nacional das cidades - se uruguaia ou paraguaia, por exemplo - que ampliam o banco de dados. Além do banco de dados produzido, é sempre interessante investigar outros já realizados por pesquisadores. Mesmo que não sejam do mesmo objeto, como no caso a Rede de Mercocidades, pode ser sobre um semelhante, como de outra rede que irá contribuir e muito na determinação das variáveis e da forma de coleta e organização dos Conjuntura Global, Vol. 4, n. 1, jan./abr., 2015, p. 10-17. 
dados. Vale ressaltar que as variáveis são sempre determinadas pela problemática de pesquisa e sua hipótese. Com isso estudos mais quantitativos nas Relações Internacionais, sobretudo diante de novos atores e suas instituições, poderão ser ampliados. A transformação dos dados de fontes como atas, com maior facilidade de uma leitura qualitativa pode ser transformados em dados quantitativos que instrumentalizam pesquisas cujo número de casos torna-se elevado e o tempo escasso.

\section{Considerações finais}

Como em qualquer trabalho empírico escolhas devem ser realizadas para possibilitar a operacionalização da pesquisa - desde o objeto até as variáveis que serão analisadas exigem uma compreensão sobre o tema a ser tratado. As variáveis não surgem dos métodos, mas, sobretudo, da problematização e sua hipótese, definindo o que torna-se importante investigar no sentido de explicarem os acontecimentos em questão. Incorporar um estudo empírico aos trabalhos de Relações Internacionais pode proporcionar maior sustentação a uma hipótese de pesquisa em números de casos elevados, o que, neste caso específico, possibilitaria maior amplitude na avaliação sobre a participação das cidades envolvidas no estudo de Mercocidades.

O que se pretendeu com o presente trabalho foi mostrar o uso de dados empíricos em um número elevado no estudo das Relações Internacionais, mais especificamente no estudo sobre cooperação descentralizada e suas fontes de dados providas por instituições internacionais como a Rede de Mercocidades. Os desafios diversos que fontes documentais podem criar, como visto ao longo do trabalho, exigem um cuidado nas considerações sobre os dados gerados e apresentados nos gráficos. A inconstância na disponibilização e a alteração do cenário de cada reunião presente nas atas, por exemplo, não explicam tudo por si, mas exige-se uma análise mais ampla. Por exemplo, durante os anos de 2010 e 2012 a cidade do Rio de Janeiro manteve-se em uma participação muito baixa, mas nas próprias atas, em seus conteúdos, indicava que foram anos em que a cidade sediou grandes eventos aos quais a Rede de Mercocidades participou. Com isso a presença 
pontual nas Unidades Temáticas não refere-se ao desinteresse, mas a uma outra atividade tão importante quanto, que apenas uma análise de conteúdo percebe e explicaria sobre os dados quantitativos.

Dessa forma ressalta-se novamente que somente o uso de dados empíricos não é suficiente para realizar uma análise da participação das cidades nas Unidades Temáticas e nem identificar a saúde da Rede Mercocidades. Faz-se necessário também levar em consideração o contexto no qual está inserido cada Unidade Temática e os interesses das cidades participantes da mesma diante de períodos e temáticas. As leituras de dados quantitativos devem respeitar os limites do objeto e, se tratando de Ciências Humanas, mais especificamente de Relações Internacionais e suas instituições e agentes, é preciso contextualizar com perspectivas teóricas e um olhar atento para defender qualquer hipótese a partir da interpretação dos dados coletados e inseridos em um trabalho.

\section{REFERÊNCIAS}

BARBETTA, P. A. (2006). Estatística Aplicada às Ciências Sociais 6 ed. Florianópolis, Editora da UFSC.

MERCOCIDADES (2015). Documentos. Disponível em: http://www.mercociudades.org/pt-br/node/2100 acesso: abri 2015. 